\title{
Learning to Be a Postgraduate Tutor in a Mathematics Support Centre
}

\author{
Michael Grove ${ }^{1}$ (1) $\cdot$ Tony $^{\text {Croft }^{2}}$
}

Published online: 20 May 2019

(C) The Author(s) 2019

\begin{abstract}
The study reported here investigates the role, experiences and aspirations of a community of mathematics postgraduates as they learn to tutor in a mathematics support centre in a research-intensive university. This is achieved through in-depth interviews with nine postgraduate tutors all of whom had experience working in the centre. The data is analysed through the lens of communities of practice and presented through the voices of the postgraduates themselves. It sheds light on their personal trajectories as 'newcomers' to the peculiarities of tutoring within a mathematics support centre, and the ways in which they learn from, support and cooperate with each other in their common endeavour. As the postgraduates progress through their three or four years working in the centre the data reveals a growing confidence and, for some, a strong willingness to nurture and encourage their younger colleagues. Some of the 'old timers' go on to assist in the recruitment of new tutors and demonstrate insights into the ways their experience as tutors in the support centre will inform and influence their own future careers as academics. In particular, our work highlights the ways in which tutoring in the centre contributes to their own mathematical learning and personal development. The work is driven by a need to better understand the practices of postgraduate tutors in the growing field of university mathematics support and a desire to improve these. We consider how what we have learned can be put to use both in mathematics support centres and in university mathematics education more generally. By doing so we contribute to the solution of a widely reported 'mathematics problem' in higher education. At the same time this work strengthens what has been described as a 'fragile' relationship between mathematicians and educational researchers, bridging the gap between theoretical understanding and practice in a research-intensive university mathematics department.
\end{abstract}

Keywords Mathematics support · Postgraduate tutors · Community of practice

Michael Grove

m.j.grove@bham.ac.uk

1 School of Mathematics, University of Birmingham, Birmingham B15 2TT, UK

2 Mathematics Education Centre, Loughborough University, Loughborough LE11 3TU, UK 


\section{Introduction and Background}

University level mathematics support has been defined by Lawson, Croft and Halpin $(2003$, p9) as "a facility offered to students (not necessarily of mathematics) which is in addition to their regular programme of teaching, lectures, tutorials, seminars, problems classes, personal tutorials, etc.". The most common model that is used is a 'drop-in' centre which offers one-to-one support to students who drop-in at a time of their choosing. The establishment of such centres represents one way in which many UK universities have responded to the challenges mathematics educators face at the school/ university transition. This so-called 'mathematics problem' can be summarised as the under-preparedness of new undergraduates (primarily in non-mathematical sciences disciplines) for the mathematical and/or statistical demands of their degree programme (Hawkes and Savage 2000). These challenges have been articulated in the UK's Post14 Mathematics Inquiry's conclusion that "higher education has little option but to accommodate to the students emerging from the current GCE (General Certificate of Education, i.e. pre-university schooling) process" (Smith 2004, p95). More widely, in both Ireland (O'Sullivan et al. 2014) and Australia (MacGillivray and Wilson 2008) mathematics support centres are also a recognized means of responding to difficulties in learning mathematics encountered by students when starting their university studies.

The case for mathematics support centres has already been made extensively (e.g. Tolley and Mackenzie 2015). While their greatest benefit is the availability of focused one-to-one support as an immediate response to specific problems, student users also comment on the importance of the atmosphere and learning environment, an increase in student control and lack of time pressure, and the informality and psychological security of centres (Lawson et al. 2001). Solomon et al. (2010) describe their role in the encouragement of undergraduate learning communities, particularly for mathematics specialists in the later years of a degree, and Solomon and Croft (2016) in engendering positive attitudes to university study of mathematics and overcoming widely-reported alienation from the subject even amongst those who choose to study it at university.

Within many mathematics support centres postgraduates working as tutors are at the frontline in providing support to undergraduates with their learning of mathematics. Their role consists of working with students, typically on a one-to-one basis, to try and understand their mathematical problems and then offering advice, guidance, motivation and support to help the student successfully work through these issues. While the impact of mathematics support upon institutions, and the students themselves, is becoming increasingly understood (Grove et al. 2019a; O'Sullivan et al. 2014), there has been little work to date exploring the lived experiences of those individuals who provide this support although some have commented upon the role of the postgraduate tutor in this process (e.g. Foster 2005).

Our goal here is to investigate postgraduate tutors' perceptions of their role in a mathematics support centre and report on ways that they say they have developed and learned through the experience. We want to understand their day-to-day experiences in the centre and how they react to contingencies that arise. We set out to explore the extent to which these tutors share a common purpose and support each other in their endeavours. In the research reported here, data from the perspective of the postgraduate tutors, collected through nine in-depth interviews, is used to explore the nature of their 
working in mathematics support and the crucial role of the community of which they are part. We aim to achieve this goal through an analysis that draws upon the theoretical perspectives of communities of practice.

The authors have been at the forefront of establishing mathematics support centres throughout the UK and of developing and delivering training for those who work in them (Croft and Grove 2016). They have been instrumental in the design of higher education policy in respect of mathematics support centres (e.g. Mackenzie et al. 2016). The research reported in this paper combines a drive for understanding the community of postgraduate mathematics support tutors - framed using existing theoretical understanding of communities of practice - with a desire to improve the practice of those involved. This work can be regarded as 'use-inspired basic research', located in the socalled Pasteur quadrant (Stokes 1997) and as bridging the gap between rigorous theory and practice-based evidence. As such it makes a significant contribution to strengthening of what Nardi and Iannone (2004, p401) refer to as "the fragile, yet crucial relationship between mathematicians and researchers in mathematics education".

We consider how this understanding can be put to use both in mathematics support centres and in university mathematics education more generally and by doing so contribute to the solution of the previously noted and widely reported 'mathematics problem' in higher education.

\section{Context of the Study}

The research took place in a research-intensive English university. The University has a drop-in mathematics support centre, established in 2012, and based in the University Library. As is common practice the centre is equipped with student workspace, whiteboards and access to computing facilities. It opens for six hours daily during term time and students from any discipline and at any level of study can drop in to ask for specific help with mathematical or statistical problems arising in any of their courses. While the University Library manages the centre (within a wider student study skills support operation) academic oversight (including the recruitment and training of tutors, responding to tutor queries and concerns, ongoing liaison with the tutors, and the monitoring of the quality of the support) is provided by the University's School of Mathematics by a named member of the academic staff, herein referred to as the 'centre manager'. A particular characteristic of the centre, and one that distinguishes it from many university support centres, is that its tutors are exclusively recruited from the School's large (approximately 60 in 2017/2018) postgraduate population. Tutors always work in pairs for typically three hours at a time and receive hourly payment. These tutors are drawn from all three or four years of their postgraduate lifetimes, with first years being relatively new to tutoring, and others having worked in the centre for between two and four years. Within the School, approximately $55 \%$ of postgraduates undertake their research in pure mathematics and $35 \%$ research in applied topics; the remainder work in management mathematics and statistics. As we shall see, this split is not reflected in the proportions of each group that work as tutors and the interviews will reveal how this situation is mitigated. There is a strong gender bias amongst the School's postgraduate 
population (approximately $80 \%$ are male) and this is reflected in the number of male/female tutors who work in the centre.

All new postgraduates involved in teaching within the School receive a compulsory mathematics-specific one-day training session as described in Grove et al. (2006). While broader than the training model described in Croft and Grove (2016), which is widely used for those working in mathematics support, it contains elements highly relevant to working in a support centre, for example presenting and communicating mathematics and problem solving. A briefing is arranged with those postgraduates who express a desire to work in the centre to discuss what the work involves, common issues and challenges and strategies for providing support. This meeting includes representation from tutors with significant experience so that this can be shared and questions answered. Following this meeting, new tutors are scheduled trial (but still paid) sessions alongside a more experienced tutor. After this, feedback is sought from both tutors, and as appropriate, an informal debrief held. If the sessions have progressed well, and all parties are happy, the new tutor is added to the termly centre rota.

When the centre described here opened in 2012, it did so with the aim of providing students with an additional source of support to aid their learning of the mathematical components of their programmes of study. Whilst accessible to all learners within the University, it was particularly targeted at foundation and first-year undergraduates and at students from other year groups identified as having particular difficulties with introductory mathematical and statistical techniques. In its first year of operation, it received a total of 482 visits, of which $85 \%$ were from students on programmes that would be classified as science, technology, engineering and mathematics, and the remainder by students studying other programmes such as economics, business, geography and sports science. By 2015/16 the total number of visits increased to 793. For the start of the 2016/17 academic year, the centre moved to a purpose-built location within the new main University Library which was in a much more prominent location. As a result, in 2016/17, total visits increased to 980 .

A particular characteristic of this centre, and one which is highly relevant to the work herein, is the students who make use of it. Beneath these headline figures it is interesting to note that as a percentage of overall visits, the number made by students from the School of Mathematics increased from 34\% (163 visits) in $2012 / 13$ to $80 \%$ (786 visits) in $2016 / 17$. It is very much the case now that the majority of users of the centre are specialist, that is single or joint honours, mathematics students. Further, and unlike many other centres, the majority of student users are in fact second and third year mathematicians: considering 2016/ 17 alone of the 786 visits made to the centre by mathematics students, $39 \%$ were in the second year of their studies, and $41 \%$ were in their third year. As such the centre described here is, importantly, not one which works primarily with non-specialist students at the transition into university which is the case often reported. While we do not discuss here the impact of the centre upon the students who choose to make use of it, its impact upon specialist mathematics students has recently been explored elsewhere (Grove et al. 2019b). The findings from this work show that students value the centre because of the convenient availability of support, its personalised nature with friendly tutors of a similar-age and subject profile, and the opportunity to use the centre as a group study space to work with friends. 


\section{Theoretical Foundation and Research Questions}

For the analysis of how the postgraduates learn and develop, their participation as mathematics support centre tutors and their personal trajectories through this role we draw upon the theoretical perspective of communities of practice. This term was first used by Lave and Wenger (1991) to describe learning through practice and participation, emphasising the importance they attached to learning in a social setting (situated learning) in contrast to that of traditional learning theories. They go on to define a community of practice as a group of individuals who come together to share common interests and goals, with the aim of sharing information, developing knowledge and developing themselves both personally and professionally. Lave and Wenger (1991) also introduce the concept of legitimate peripheral participation to describe the way 'newcomers' to a community become drawn into a practice, develop and eventually (some) become 'old-timers'. Wenger, McDermott and Snyder (2002, p4) later defined a community of practice to be "groups of people who share a concern, a set of problems, or a passion about a topic, and who deepen their knowledge and expertise in this area by interacting on an ongoing basis". In their paper expressly studying specific practices within a university, and especially those that concern the teaching and learning of mathematics, Biza, Jaworski and Hemmi (2014, p162) define a community to be "a group of individuals identifiable by who they are in terms of how they relate to each other, their common activities and ways of thinking, and their beliefs and values". Lave and Wenger (1991) suggest that the process of learning should offer individual learners opportunities to participate in the practices of a community whereby individual identity is engendered through a sense of belonging and commitment to the community. We shall see that using the framework offered by this theory enables us to examine systematically the community we are researching.

We now briefly describe relevant aspects of the elements of the theory. In Wenger's social theory of learning (Wenger 1998, p5) four components are identified: meaning, practice, community and identity. Meaning, or learning as experience, refers to the ways in which members of a community understand and talk about the environment in which they work, the activities in which they participate and their abilities to undertake the tasks necessary. As Wenger (1998, p53) notes, the making of meaning requires negotiation - "continuous interaction, gradual achievement, give-and take". Thus meaning can be changed through experience and negotiation. Practice, or learning as doing, refers to the perspectives members of the community adopt and resources they draw upon in their practice, on a day-to-day basis, which help to maintain their engagement in pursuit of the enterprise they are undertaking. The component community, or learning as belonging, represents the ways in which members talk about and draw upon the community, its structure and the way it functions. Identity, or learning as becoming, is concerned with the ways in which the learning that takes place impacts on and can change the members themselves.

Wenger (1998, p73) defines practice through three dimensions of: mutual engagement - ways of working, how this work can be done differently or better through observing and interacting with others, social relationships; joint enterprise - the negotiation that takes place to develop common understandings of what the enterprise is about, discussions of accountability, responses to local contingencies; and shared repertoire - resources through which meaning is negotiated, routines, words, 
discourses, tools, actions and "concepts which the community has produced or adopted in the course of its existence". Wenger (1998, p55) refers to two further concepts of relevance here: participation and reification. Participation refers to living or being within the community and taking part in its activities, interacting and negotiating and more. But it goes beyond simple engagement: as Wenger notes, participation is not something that is turned off once the specific context of engagement ends. Its effects will permeate other areas of the members' lives and as such is a constituent of their identity and will help shape it. Reification refers to the representation of some abstract concept by something more material and concrete and plays an important role in the negotiation of meaning. Wenger (1998, p. 58) states, "We project our meanings onto the world and then we perceive them as existing in the world, as having a reality of their own". So, for example, being an 'effective' community member is a rather abstract notion that might be reified by projecting the meaning of 'effective' onto more tangible attributes such as the skills a member has and the uses to which they are put. Given time and usage such a reification can start to take on a life of its own and contribute to the shared repertoire. Participation and reification are viewed by Wenger as being intimately connected because reification is crucial to the negotiation that is necessary for participation.

Communities of Practice theory has previously been used to explore learning in both formal settings such as schools and informal settings such as apprenticeships and playgrounds. Biza, Jaworski and Hemmi (2014, p161) have discussed extensively the theoretical foundations of communities of practice in university mathematics and describe learning as "a process of participation and reification in a community in which individuals belong and form their identity through engagement, imagination and alignment". Again in the university mathematics context, and specifically in respect of students working as partners in the teaching and learning process, Duah (2017) has used the theory to analyse both academic internships and peer-assisted learning highlighting the contribution that students themselves can make in improving the experience of mathematics undergraduates.

We now turn to the research which is the focus of this paper. The postgraduates who work in the centre are engaged in activities which go beyond that found in their usual university practice. Traditionally, in addition to their day-to-day research work, mathematics postgraduates undertake problem classes for specific taught undergraduate modules, where the course leader, a university lecturer or professor, will provide problem sheets for the undergraduates to work through, together with solutions for the use of the postgraduates. They may also undertake marking of assessed coursework and computer laboratory supervision. On the other hand, and crucially, when these postgraduates work in the support centre, the nature of the work is quite different in several important ways. Firstly, they have no prior knowledge of a student who walks into the centre seeking help. The student could be studying in almost any discipline (for example bioscience, economics, engineering, in which case such a student may not have studied mathematics beyond GCSE, i.e. beyond the age of 16) including mathematics. They could be from a foundation year, with or without an A-level in mathematics, a final year project student or a postgraduate masters or research student, and anything in between. This makes finding the appropriate level to pitch a response particularly challenging for the tutor. Secondly, they have no prior knowledge of the question they are likely to be asked. They must quickly learn to think on their feet and 
be willing to explore and research possible solutions in partnership with the student. For these reasons it is difficult to prepare for sessions - a marked distinction from the module problems class which is highly focussed and for which lecturers' resources are available in advance. On the other hand, to counter these two differences, the flexibility of drop-in centre work can often permit a tutor to spend longer time with a student on a one-to-one basis, to work together on a particular problem and to come jointly to a solution. Moreover, there is also the possibility of either referring to or working with the partner tutor on duty in the centre at the same time, or the wider mathematics postgraduate community as we shall see.

Thus postgraduates must learn to become mathematics support tutors. They do not do this in isolation. With just one day of formal training, their substantive learning is truly situated and takes place in the context of their participation in the life of the support centre. As the data will show, there is a strong network of other tutors upon which they draw and to which they contribute. We see this learning as taking place in the social context of their interactions with students, their postgraduate partner tutor in the centre, the wider group of postgraduate tutors and the academic lead in the School. We are interested in how the tutors make meaning of their role and in the negotiation required - for example, interactions, discussions, tensions, disagreements - to achieve this. We are interested to learn about the extent of collaboration between tutors - for example, the advice and support they offer each other - and between tutors and students who use the centre. To accomplish our overarching goal of understanding the role played by the tutors who work in the mathematics support centre and how they learn and develop through this experience we asked two research questions:

a) What is the role and extent of negotiation and collaboration in postgraduates learning to become mathematics support centre tutors?

b) What is the nature of this negotiation and collaboration and what is its impact on individuals and on their self-reported practice?

In this paper, we aim to respond to these through an analysis that draws upon the theoretical perspectives of communities of practice outlined above. Whilst the research questions arise pragmatically from a need to better understand the ways in which tutors work, the chosen theoretical perspective influences the data collected, how it is collected and how it is analyzed. There is a reflexive process between the research questions and the theoretical perspective which influences how we address the interview questions and how we interact with the participants. It follows that semistructured interviews were an appropriate means of data collection. Further details are given in the following section.

\section{Methodology}

For the semi-structured interviews, pre-prepared questions, which had been provided to the participants in advance of the interviews, covered five key themes: the mathematical background of the tutor, their ambitions and motivation for working in the centre; what the tutors know and think about mathematics support; the practices tutors adopt whilst working in the centre, the ethos of that work; tutors' views concerning 
postgraduates working in the centre; and, the skills and qualities tutors think they have been able, or hope, to develop through this work. Illustrative interview questions are provided in Appendix 1.

Whilst these questions gave focus to the interviews, the interviewer worked with prompts and sub-questions to follow up participant's responses. They were encouraged to speak freely about any aspect of this work they thought pertinent. In the spring of 2018, of the postgraduate population eligible to undertake teaching duties within the School, 21 were working, or had worked previously, in the mathematics support centre. All 21 were invited by email to participate in this research via interview; nine responded with a willingness to do so. Whilst we acknowledge that this is a selfselecting sample they are nevertheless representative of the tutor population as a whole. Table 1 provides biographical information on the nine participants, outlines the splits between pure and applied mathematicians and genders, and the lengths of their experiences as tutors in the centre. We interviewed the nine postgraduates over two days towards the end of the academic year in July 2018. The individual interviews were conducted by one of the authors who had no involvement with the postgraduates either in their work in the support centre or more generally in the School; nevertheless he had extensive experience of working in a support centre and therefore was aware of the issues that can confront a tutor. Each interview lasted approximately $45 \mathrm{~min}$. The interviews were audio recorded and then transcribed.

Ethical approval was granted by the University. Appropriate ethical guidelines (BERA 2011) were followed. A description of the research was made available in advance, and at interview, all participants signed informed consent forms detailing how the collected data would be used.

The data thus gathered provided rich and complex narratives for each of the nine postgraduates. We chose to proceed thematically (Braun and Clarke 2006) and by following the coding process described by Creswell (2008). Thus, the analysis began with reading and re-reading the transcripts, and listening to the audio recordings to allow us to become familiar with the depth and breadth of the content and begin organizing the data. As noted above the interviews were conducted by one of the authors who also produced the transcripts, a key factor

Table 1 Data on the nine postgraduate tutors who were interviewed

\begin{tabular}{lllll}
\hline Tutor & Gender $(\mathrm{M} / \mathrm{F})$ & Pure/Applied & $\begin{array}{l}\text { Academic years completed } \\
\text { by Summer 2018 }\end{array}$ & $\begin{array}{l}\text { Number of years tutoring } \\
\text { in the centre }\end{array}$ \\
\hline A & M & Pure & 1 & 0.5 (one semester) \\
B & M & Pure & 2 & 2 \\
C & F & Applied & 2 & 1 \\
D & M & Pure & 3 & 2 \\
E & M & Pure & 2 & 1.5 \\
F & M & Applied & 1 & 1 \\
G & M & Pure & 4 & 3.5 \\
H & M & Pure & 2 & 2 \\
I & M & Pure & 2 & 2 \\
\hline
\end{tabular}


which helped in this familiarisation and data immersion process and enabled insights to emerge. In-depth discussions of the data and its classification were undertaken throughout the analysis with the second author which formed an important check of validity (Creswell and Miller 2000). The following broad categories for data classification had been predetermined having been generated from Wenger's components and dimensions of communities of practice and the concepts of participation and reification:

- Components of learning: meaning, practice, community, identity;

- Dimensions: mutual engagement, joint enterprise, shared repertoire;

- Participation;

- Reification.

Then, working systematically, each transcript was read again, this time assigning the above categories to segments of text. Due to the small size of the data set, this process was performed without the use of software. So, for example, when Tutor $\mathrm{H}$, describing the difference between tutoring in a module problem class and in the support centre stated "In the support centre you can get asked about absolutely anything. So you don't have preparation - you have to improvise as you go along" this was categorised under 'practice - learning as doing'. When asked how they might help a student when they did not have the required knowledge they stated "what I usually do is direct them to some other postgraduate in the support centre" and this segment was assigned 'joint enterprise'. As relevant text segments were being categorised descriptive codes were generated "in vivo" (King 2008). For example, when Tutor A stated "I would basically guide them in this process of let's do things bit by bit." this was assigned the code 'scaffolding'.

Repeated consideration of these categories and codes enabled us to draw together interesting commonalities and differences amongst the participants, particularly in respect of how they were learning and developing in their role and the importance of interactions. We choose, following Wenger (1998), to report our findings using the four components, learning as: experience, practice, belonging and becoming, presented from the perspectives of, and through the voices of, the tutors.

\section{Analysis}

\section{Learning as Experience}

To establish a background to their role, postgraduate tutors were asked about their knowledge of the purpose of a mathematics support centre and what they understood to be their role within it. They demonstrated considerable empathy and an understanding of the many reasons why students might access mathematics support and in particular that it may be more accessible to students than other forms of assistance. Some tutors reflected on their own experiences as undergraduates and recalled the difficulties they faced. They are aware that students can find both mathematics and mathematics academics intimidating and that they, as postgraduates might be less-so. Their views reinforce the findings of Solomon et al. (2010) who describe support centres as 
'physical safe spaces'. Convenience and informality of the learning environment also come to the fore, as noted by Lawson et al. (2001).

Tutor B: ...you have...people for a whole range of reasons. People don't like knocking on professors' doors, it's much more approachable to go to young people your own age and get help; relaxed, readily available - the way it's there all day, if you're struggling it's something you can go in anytime.

Tutor G: Well one of the big issues with maths is that...it's a scary world, a lot of people very often in the university will struggle because of curriculum issues, from being from another country, or not having done modules, or just because they find it hard...like when I was an undergraduate it was always very, a bit harder to go and talk to a lecturer about problems whereas postgraduates are more approachable in that sense.

Tutors were asked about their motivation for becoming involved in the work of the centre. Several, expectedly, referred to the remuneration which was clearly welcome. However, many went on to describe the intellectual challenges both mathematically and pedagogically that they expected to face, how they liked teaching, and the skills that they intended to develop. They recognised in this work the opportunity not only to acquire and advance their pedagogical expertise, but also to hone and expand their own mathematical skills:

Tutor I: I quite like trying to teach things, at least at an undergraduate level because the problems aren't trivial normally...you have to have a think about them. So to come up with a way of doing it yourself is great and also trying to work with the students and make them understand what is going on.

In terms of Wenger's component of identity and learning as becoming, (see later section 5.4) they saw this work as providing an opportunity for them to broaden what they do professionally, and to learn how to adapt their teaching styles to accommodate a broad range of learners:

Tutor D: ... a skill that I always wanted to get better at is, it's not quite public speaking, but more to deal with people in a professional environment, to be able to adapt my teaching style to different people who might learn in different ways.

They also referred specifically to the skills that they hoped to be able to develop through working in the centre. These included being able to respond to unforeseen and unfamiliar problems, and to devise alternative methods of solution or explanations tailored to individual's needs:

Tutor D: It's quite a good challenge because anyone can walk through those doors; you can't prepare for everything obviously, but you have to be prepared to try and tackle anything and that's a good skill to have. Something that I found really useful is when you try and help someone and they say 'I don't understand your explanation' and you have to go right back to the drawing board. You've got to think of another way of getting to the same answer. 
Tutors were well aware that they would need to work with students from a variety of discipline areas. In fact, the opportunity to work with students from disciplines other than mathematics was a draw for some of the tutors, particularly in how they would learn to transfer their mathematical knowledge into new and unfamiliar domains:

Tutor F: ...it's a different kind of experience that you get from doing normal teaching because that's just mathematicians; so I'll have people from, you know, from chemistry, geography, physics from different backgrounds asking for different maths help and you have to translate how you interpret maths to someone with a different background. It helps maybe train me in a way that just doing normal teaching...wouldn't allow.

\section{Learning as Doing (Practice)}

In this section we consider the descriptions the tutors provide of their practices whilst working with students, the resources upon which they draw to support this practice, and how, through experience gained, they learn to evolve their practice.

\section{Working with Students}

To learn to work in the support centre tutors must be able and willing to think on their feet. There are important differences in approach depending upon whether the tutor is familiar or unfamiliar with the mathematics with which they are presented, and as a consequence, the extent to which they seek help from or offer help to other members of their community.

When the topic is familiar the tutors are able to offer scaffolding (a range of teaching techniques and explanations used progressively to move students toward greater understanding) and make up their own examples as they are working with the student. The following illustrative quotes demonstrate that some tutors possess good levels of pedagogical maturity: working to and fro with students to gauge their level of understanding and knowledge. They have the confidence to probe rather than 'tell'. They recognise the importance of drawing out solutions from the students themselves. They are willing to challenge. Consider, for example, Tutor B:

Tutor B: I will try and gauge where they're at. I ask them questions, you probe them a little. If it's part D you ask them how they did in Part C. You ask them...you never just show them the answer. You're constantly asking them questions and almost make them answer it themselves...I guess you learn through time that if you show someone the solution they don't understand it as well than if you make them come up with the solution themselves, and you can pick up on it - you can feel the penny drop...

Tutor B, explicitly referring here to him learning through time the importance of engaging the students actively, reflects a deepening insight and the development of a 'teacher identity'. Likewise, Tutor H, insists that the student is an active learner: 
Tutor H: So, I do remember, this past year there was a student who would come asking for help with the graph theory module and they were all problems that I could easily solve. What I would do is I would force her to do it. I would give them a pen for them to go to the white board and for them to write down everything that the statement says.

Tutor H, went on to offer a strategy for problem solving but insisted that the student took ownership:

Tutor H: ...because very often there is a lot of information in the statement and people become confused and do not know what to do with all of the information. What you need to do is write [down] the information and then try to combine the bits one by one to reach the conclusion that you want. So I make them go to the white board and write everything down. And you could do just small pieces and then just put them altogether to get the result. I would basically guide them in this process of let's do things bit by bit. Looking to this - just this - I know you can solve that - they solved it.

The importance of probing in unearthing student's difficulties is evident in this quote from Tutor G:

Tutor G: Do you understand what the statement says? An issue with this approach is that often they will say yes, and then when you ask them what does that word mean, they say no...And something I have found out is that very often just by clarifying this word, at some point the student will say, oh can we try something like this. They may be right or not, but very often just at least that discussion is already a help.

Sometimes however, this familiarity with the mathematical topic can lead to ways of working which are short-lived and need to be modified. This tutor described how, by drawing upon his own knowledge, understanding and approach to tackling a particular problem, which differed from that taught to the student, he caused more confusion. In recognising this he learned to adapt his teaching accordingly:

Tutor G: And if I know about the topic - I may know about the topic but from a different angle, or I may have learned it differently, so very often I always try to follow their lecture notes because at first I tried to do it the other way and sometimes I confused people...[we needed to use] some fairly advanced results that I find almost trivial, or I am so used to them that I use them without thinking and I could be using something from later in the course to...presume something...

Adaption to individual students' needs was evident. The following excerpt describes how Tutor D became aware that the abstract nature of a particular topic in linear algebra was causing difficulties for a student who he thought might benefit from a more concrete approach, and how he modified his own approach accordingly. He was able to reify abstract notions as they had been taught by the lecturer, referring to the more familiar and concrete cases of two 
and three dimensions, and through analogy believed that this provided the insight required to help the student:

Tutor D: ...there was one student [struggling with] these notions of dimension, basis; so one way of doing that is to go very abstract, to go from the definitions, and after this explanation it was quite clear that the student was not getting this so I went back to the basics, back to the example of Euclidean space, you have these standard basis vectors, so in two dimensions you get the square and in three dimensions you get the cube etc... and explaining everything through analogy with that.

Tutor D went on to explain his strategy of explaining an abstract concept to this student not through a definition, which is the usual approach adopted in advanced pure mathematics courses, but by starting from an example and using that as a way into understanding the formal definition. As he said: "and supplementing with the definitions rather than going straight from the definitions, helped that student."

The foregoing excerpts are typical of the approach adopted when the tutor was familiar with the mathematics. However, on many occasions students, particularly from disciplines other than mathematics, or those studying advanced mathematics degree modules, ask for help with material which is completely beyond the experience and expertise of the tutor. The interviewees were asked about their strategies for dealing with such situations. The response depended upon whether a second tutor with the requisite knowledge was available at the time or not. The following demonstrate the extent to which the tutors value and draw upon the support of their peers in the community:

Tutor A: ...the ideal situation is because you are working in the support centre with two people, I have been fortunate enough to have - most of the time - the other person with me is someone who either was at [this University] before and took the course or someone who is working in that field of research.

Tutor C: ...my pure maths is fairly poor. Just because I did an applied masters. So basically I could do second year fairly comfortably but if a third year came in, rather than me spend hours trying to read around it, you know I'd be better off sending them to another postgraduate.

But what happens when neither of the available tutors is a specialist? Neither knows how to solve the problem. It is evident that at this stage some tutors see the task as a joint enterprise and work together to try to come to a solution which will assist the student:

Tutor B: But it's when someone comes in with something that neither tutor is a specialist in - someone comes in with a partial differential equation or something, and it's me and a statistician or something - then we'll kind of bandy our strengths together and see what we...not always, but it does happen sometimes and I think that's a good thing too. Strength in numbers, and support each other as well...

Tutor $\mathrm{H}$ offers an interesting problem-solving perspective in what follows, demonstrating the value of two tutors approaching a problem in different ways, 
one the 'brute-force' approach and the other bringing insight and elegance to the process:

Tutor H: ... if it's something that neither of us have expertise on we usually try and work together. I can think of some instances with - I think second year analysis - when you have to consider integrals in higher dimension which again is something I haven't looked at in many years. Very often there are some symmetries in these problems so while one person focuses on what the theoretical brute force solution would be, the other person can think about how we can simplify the problem by getting rid of this half and just multiplying by two, and things like that.

But what happens when the second tutor is already occupied helping someone else? When asked about how they deal with advanced, unfamiliar material, and when they have no immediate postgraduate peer help to call upon, they demonstrate a keen willingness to work with the student to learn together. They were also well aware of how their 'ignorance' can be turned into learning opportunities for the student often resulting in the student solving the problem for themselves and coming to a greater understanding (for both parties) through the negotiation that was taking place:

Tutor A: ...they'll have to explain the problem to me...either I will understand it and be able to assist them, or the process of them speaking it out loud to me is sometimes enough to motivate them to have the thought that solves the problem.

Thus dialogue and negotiation of meaning are crucial elements through which both tutors and students are learning in the support centre. In the following excerpt Tutor A asked the student to illustrate a problem using a diagram and this was sufficient for the student to come to a solution themselves:

Tutor A: I think the thing I can remember is random walks in combinatorics...they couldn't understand this and I was like - well explain it to me - and they were trying to use words and I was like why don't you draw me a picture of what this random walk could look like; and they drew the picture, and they went...that this could happen, and then as they were drawing the picture they were like well that can't happen, and you ask a simple question, why can't that happen and they say it can't happen because we have this property and you say well turn it into a solution...

Enabling students to see that the tutors do not know all the answers but even then that they can demonstrate problem solving strategies is evidently one of the benefits of learning in a support centre environment - and one which is not normally apparent in a lecture or problem class.

Tutor B: People have come in with their undergraduate thesis and all kinds of stuff where they have papers, maybe something I am not familiar with...we just kind of sit down together, read through it. I do the best I can.

Interviewer: Is it a process of trying to feel your way through it together? 
Tutor B: I think that helps them a lot as well. I think when they see the process of the instructor figuring it out, walking them through it, I mean it's not staged or anything, it's the genuine thing of this person beside them trying to figure it out just the way they've been trying to figure it out.

The idea that the tutor too struggles and that it is important for students to see this was evident in several interviews as Tutor H's quote illustrates:

Tutor H: I do remember a problem about optimisation which also required tools from linear algebra...I think the module was a third year module, but the linear algebra tools were first year tools. I did spend about 20 minutes only to understand the notation and the problem. Once I understood everything I just realised, ok this is first year linear algebra, I can solve this. They were sitting with me and they saw that I was struggling and they were trying to explain to me the notation too, which is good.

Tutors were able to be quite specific about mathematical areas where learning collaboratively was crucial for progress. Here, Tutor $\mathrm{F}$ refers to reading lecture notes together, highlighting important parts and making suggestions which lead to success:

Tutor F: So this module called continuum mechanics that the third years do in the first term. That's quite abstract stuff so you need to know the lecture notes - it's different from a lot of other courses - I didn't have any experience with...I didn't know the material. So there was one question where you were trying to convert one form of a partial differential equation into another using manipulations you learn in class. So we just kept on looking at this example and I said, oh they've done that in this example, have you done this, and this time it was no, so I said try that - I just sat by him while he was working it through it...that worked.

Even when the solution of a problem defeats both the tutor and the student some tutors believe that there are learning opportunities for both parties. In what follows Tutor D, even though he could not solve the problem in-hand, talked through his strategies, explaining his thought processes, and importantly, what he was doing and why. This dialogue is invaluable for the student and is an excellent demonstration of the perseverance that undergraduate mathematicians need to develop:

Tutor D: Yes - we were doing all these crazy things...in terms of results it was a wasted half hour because they didn't get the answer but I hope it was useful trying to...so everything I was mentioning I was talking through why I was thinking this might...In those situations the strategy is quite important to get across. Right, I am going to try this - this is why I am going to try this - this is what I am hoping will happen when I try this. When that didn't work I go back to the drawing board. What can we try next? 
This was not the end of the matter. Here we see an excellent example of how Tutor D did not simply 'turn off' his engagement at the end of the session, but the problem stuck with him and bothered him for quite some time:

Tutor D: This problem stuck with me - because I'd spent half an hour on it, I couldn't do it. Eventually I had to say - look, I'm really sorry but I can't. I asked the other postgraduate - they couldn't do it either. It was really spinning in my head for a couple of weeks. Then, a couple of weeks later a different student came in with the exact same question and because I had been stewing it over a couple of days before, I had actually come up with the answer. So I was able to say, this is what we are using in this question.

This permeation into areas of the tutor's life beyond the support centre is a fine illustration of participation as understood by Wenger (1998). Moreover, by being able to draw upon what the tutor has learned outside the centre, he was able to help a subsequent student. This immersion by the tutor in the life and well-being of the centre helps to ensure that it functions effectively and, in the tutor's view, benefits students.

When the solution of the problem in-hand remains intractable - notwithstanding the work done with the student and with the second postgraduate - tutors referred to how they would frequently take the problem, at the end of the session, back to their peers. We evidence this in the section below on learning as belonging.

Some tutors highlighted differences in practice when working with students from other disciplines and how they would tailor their work to the discipline and background of the student. The following excerpt demonstrates a sensitivity to the needs of the student and a recognition that not all require the same level of rigour as a student studying mathematics:

Tutor I: Sometimes you want to tailor your responses slightly...just because the ways things are done in the maths department is always very rigorous and formal and sometimes, say engineers just get completely confused by that. Sometimes you might want to go through a full derivation and show them where it all comes from but they [engineers] just get lost half way through so you skip the middle bit and say this is essentially this, and look at it a bit, and it looks about right and they are happy with that.

Tutor I continued by explaining that, as a mathematician, he sometimes found this approach uncomfortable, but recognised this pragmatic approach was sometimes appropriate:

Tutor I: I don't like to because it's always good to have a formal approach anyway. When they can't understand the full generality you can just skip the details.

However, this was not always the case, and some tutors referred explicitly to their primary focus being the 'question' or the 'mathematics' and not the student. Tutor D was probed about whether it was important to know at the beginning which department students had come from: 
Tutor D: It probably is but I try and really focus on the question itself. It is sometimes fairly obvious. Certainly with maths [students] I am fairly familiar with which modules happen when and so this question is probably in this module this year. If they are sort of asking something outside that, that's a good indicator they are not a maths student and I maybe adjust my style accordingly. But I do try and focus on "ok this student has this problem, here is how I would normally tackle it".

Notwithstanding their earlier comments about tailoring their responses, Tutor I, when asked if they treated biology and economics students turning up at the centre any differently (from mathematics undergraduates), stated:

Tutor I: No. I occasionally have to ask what they know so that I can actually avoid just confusing them. Not really. It's about the same...Normally they just come with a question and I just start dealing with that.

We shall return to this critical issue of primary focus - the student or the mathematics - later.

\section{Drawing upon Resources}

The predominant resources referred to by the tutors are the lecture notes of the student, or the lecturer's notes available on the virtual learning environment (VLE). One tutor referred to lecture notes from modules previously studied by the student that would sometimes be referred back to:

Tutor E: I ask them, do they have their notes. I read their notes - see what they have written.

Interviewer: And when they don't have notes?

Tutor E: A lot of them do bring smart devices - laptops, tablets and stuff and I'll bring it up on there.

Tutor H: I think I have referred students to their own lecture notes both from the same module and from other modules. So if someone is asking me about a problem that I know they have solved in the previous year or I know appears in a very similar way in the notes, I just tell them look at these - it's very similar.

These quotes serve to illustrate the importance of students arriving for support at the centre with a good set of lecture notes if they are to maximise their opportunity to learn from the tutor. The provision by the lecturer of high quality notes on the VLE serves as a fall back when, for whatever reason, the student's own notes are not available.

There is some evidence that the tutors draw in an impromptu fashion upon artefacts that are available to help illustrate the teaching points they are trying to make. Here Tutor D reports how he was able to illustrate key aspects of spherical trigonometry using the hemispherical top of a water bottle:

Tutor D: The student had a very large water bottle. Let's have a look at this water bottle. The top was a hemisphere. I want to describe some point on here. So what are the two...you can describe this in two parameters. How can I describe this 
point precisely? We need to pick the latitude. Ok, how can we describe that? We've got this point, it's on this latitude; for every point on this latitude, we can describe that by this angle here. Similarly, we have this cross-section that we are on. How can we describe which point on the cross-section we are on? Well we can move around on this, so this gives us the other angle. So once they were able to say "I know what these angles mean", we were able to go back to the algebra and say that's why this expression has these two important angles and that's all we are doing.

Drawing a relevant diagram or picture was frequently referred to as a means of producing a useful learning tool, in this case a tree diagram to illustrate probabilities:

Tutor D: Let's go into the algebra - the algebra wasn't helping them. So right, let's look at this probability. Let's draw it all out as a tree diagram; so a terrorist enters zone 1. Do we detect them, do we not? If we do detect them, do we catch them or do we not catch them? So, using this we were able to isolate each part of the formula that corresponds to each of these events.

Other tutors referred to video resources available online to which they had directed students:

Tutor F: In fluid mechanics there was an enthusiastic student so we got talking more about the actual area and there's this YouTube video on laminar flows. It's quite a good YouTube video displaying this thing they see in equations, so I said this is it in real life, you know.

Interviewer: Did you show them it?

Tutor F: Yes. They seemed to find that interesting.

Practice in the centre provides opportunities for postgraduates, on occasions, to share their more general experience with the students and to explain aspects of their own research:

Tutor G: I talk to them and even sometimes some people have asked what I have been doing as part of my research...there are some second or third year keener students asking about that because sometimes they will have a module that only a few of the postgraduates will know about and they finally find someone who can help them. And then they are probably happy about that.

Finally, mathematics support clearly provides an environment in which interpersonal skills such as empathy and sensitivity can develop. These aspects are discussed further in Section Learning as becoming.

\section{Learning as Belonging}

In this section we consider the descriptions the tutors provide of how they learn through the support of the community of postgraduate tutors. They discuss the composition of that community - how it is comprised of tutors with different 
academic interests and areas of expertise (e.g. pure mathematics, applied mathematics, statistics), and how they know about these things and importantly, how they exploit these differences in support of their own learning and that of the students visiting the centre. They refer to tutors being at different stages of their academic careers, and how those with more experience ('old timers') support the newer members and assist in the maintenance of the community. They describe their understanding of what it means to be a 'good tutor' within the support centre environment, describing attributes that they have witnessed and often emulated.

There is substantial evidence that the community supports learning - but not just within the bounds of the centre a fact which further illustrates the truly participative nature of this community. Outside there are regular discussions about mathematical problems arising which tutors have been unable to resolve, pedagogical issues, and tensions and contingencies that have arisen (e.g. dealing with difficult students or peaks in demand). Collectively these characteristics help the community, and as a consequence the centre, thrive, and provide an engaging and rewarding working environment which provides an additional and welcome dimension to the academic lives of the postgraduate tutors.

\section{Drawing upon each Other}

The tutors are part of a strongly networked postgraduate community within the School of Mathematics. Not only are they all based within the same academic department, they interact professionally and socially. Many share a large openplan office space, they attend seminars and short-courses together, and they provide collective teaching support to large undergraduate modules. There is also an active postgraduate society that organises both academic events, for example research conferences and poster presentations, along with weekly social activities. The pre-existence of this network helped enable the community of tutors to thrive, to readily call upon, learn from each other's practice and help each other. They were able to articulate how they drew upon each other:

Tutor H: We pretty much have a good networking here so we know all the postgraduates in the School and you know what area of expertise they have. You know what they are working on for their PhD's. So I just try to look up the names of my colleagues and...if the student is asking me about dynamical systems I will go to someone who does analysis or applied maths who will hopefully be able to help.

Tutor B: There is two of us scheduled at any time so if the other guy or girl is specialist in this then I would bat the ball to them; if I really feel it's something out of my comfort zone I can get the timetable up. I can refer them to a slot when someone who is a specialist can...

Tutors were asked how they knew about the skills of the other tutors, and how they were able to access these. They referred to tools that assisted in this endeavour and specifically a list of tutors' skills that had been prepared: 
Tutor A: Everyone's quite aware of the areas that the other people work in at that level...we have a sheet that was sent round amongst all the tutors to say this is what we can specialise in...

They themselves had instigated technology that would enable real-time communication between a tutor in the centre and other tutors outside, referring to the 'group chat' phone apps to which they have access. Clearly, even tutors who were not directly engaged in the centre at a particular instance were participating by being able and willing to offer advice from a distance:

Tutor C: ...so I would just put a message on the group chat and say "hey can anyone do this thing? I'm struggling" and then if that person didn't reply and say "yes I could", someone else would probably reply and say "oh, [X] could probably do that".

Evidence that postgraduate tutors work together in the solution of a student's problem has been described in Section Learning as doing. The extent to which this can take place of course depends upon how busy the centre is and upon the skills each tutor has. Tutor B's comment below exhibits both an interest and a keenness to engage in the joint enterprise of helping students:

Tutor B: If it's quiet sometimes and someone comes in - some people - I would like to think I am one of them, there's definitely others - if a person comes in and they're talking to this tutor and the tutor is kind of working with them, the other person might come over as well and they'll both work together.

\section{Old Timers Supporting Newcomers}

There is substantial evidence that 'newcomers' to the practice are supported by the more experienced tutors. But the role of the old timers goes further than providing support. They provide models of mathematics tutoring. Through observation the newcomers internalize the notion of being a 'good teacher' and report how they emulate what they have seen:

Tutor H: There are quite a few older postgraduates...if I was struggling with some problem I would ask for help. There is also the process of observing how more experienced people do it and you can copy things you really like that they do, in particular this idea offorcing the student to solve the problem. I picked that up from another postgraduate who was working there.

The mere presence of a more experienced tutor in the centre with a newcomer assists in alleviating any apprehension they may have as reported by Tutor A:

Tutor A: ...in those first four weeks...I don't want to say [I was] nervous, but maybe a little less confident to just sit someone down and try to figure out a 
problem in front of them, so then you have this... a fourth year comes along who as 12 been doing this a long time and has probably come across that problem themselves - and even if they don't cover and start teaching it - it's all support...

Outside the confines of the centre, discussions continue and 'old-timers' give advice on practices and ways of recognising and responding to affective issues that students may have. This included offering reassurances to students who were worried or anxious.

Tutor F: I used to talk to a tutor called [name] - and he was really good at teaching people; he's left now, but that was outside the maths support centre he used to talk about things and say what he did and how he taught in the centre and...

Interviewer: Can you think of any specific things he advised you to do or not do?

Tutor F: ...sometimes if you have students who are getting stressed and worked up about not getting something he said like keep on emphasising, so quite often they've already done a part, say you've done that bit, so you know that stuff, you know this stuff you just need to...get more practice, and say like "oh you've got some time, this is what revision is for, you know...to learn this stuff".

Throughout the interviews the notion of being a 'good' support centre tutor was reified by the interviewees in several ways. So, Tutor $\mathrm{H}$, above, has learned that involving the student actively in the problem solving process - 'forcing the student to solve the problem' - is effective and is a characteristic of a good teacher. Tutor F refers explicitly to a peer as being "really good at teaching people" and through probing is able to concretise this in terms of having a sympathetic attitude and offering constructive advice.

There is also evidence that more experienced colleagues, spotting that there were issues arising, would actually intervene during a session and that the new tutor valued this:

Tutor F: We had this difficult student; sometimes, if he didn't get it... he'd become annoyed and it would kind of seem like he's annoyed with you. He could be quite difficult. There was also this tutor called [name] who was in the centre at the same time; she was looking over and occasionally put a word in to try to...help him...I was trying to explain things to him. She just managed to word it in a different way which actually seemed to help.

Interviewer: She wasn't intervening about his annoyance, she was intervening to try and help him with the maths?

Tutor F: Yes - to explain it in a different way...Obviously in my first year - I'd not had that much experience whatsoever. My first term, my first couple of weeks and she helped me out.

The role of some of the 'old timers' went beyond supporting their less-experienced peers. They were found to be supporting the centre manager in recruitment of new tutors and thereby helping to maintain and grow the community. Here Tutor G goes so far as to recommend working in the centre:

Tutor G: I think it's [the centre] a good idea and I would encourage all the first year postgraduates to try to do it... the new people when they come they have this 
introduction to teaching with [name]. The centre is advertised to them, and sometimes some of them are like "is it useful" or "is it not useful". And myself and lot of other tutors have tried to encourage them to help.

Through the conversations in the office, postgraduates who are not tutors are often inspired to take on the role in the future:

Tutor F: People talk about it and the other students, similar first year people this year, are tempted to do it next year, because of how I've talked about it...so from hearing what its actually like they've said ok yeah I can do that, you know.

\section{Outside the Centre - and Still Learning}

To follow up on the notion of community maintenance, the tutors were asked about the extent to which, outside of the support centre, they continued to support or be supported by other tutors. Tutor $\mathrm{H}$, here, was receptive to a request for help from another:

Tutor H: In particular there was one time when someone came to me and said "I was struggling with this problem in combinatorics that a student brought up and I couldn't solve it, how would you solve it?"

and confirmed that he did indeed offer advice. Tutor A referred to how he was able to learn something about fluid mechanics from peers in his (pure mathematics) research group because they had previously studied that module whilst undergraduates at the same university. He was later able to put this learning into practice when tutoring in the centre:

Tutor A: ... a large number of the PhDs here did their undergrad at [university] so they have taken the course. So maybe I'll talk to someone who's also in the algebra group about a problem in fluid mechanics, just because they happened to take that as an undergrad and they'll be able to answer.

Interviewer: So have you been able to learn from this other postgraduate and then go back and advise a student differently?

Tutor A: Yes, absolutely.

When discussing the nature of communication amongst the group of postgraduate tutors that went on outside the centre there were clear examples that this was taking place, in part, to forewarn colleagues about impending deadlines and likely topics that students would seek help with. Tutor E's comments are illustrative:

Tutor E: We'll have a session, we'll come out and we'll talk about what questions we got asked and how the students were. Sometimes it's like a heads-up to say oh this week many students coming to ask questions on...we find out when the deadlines are because the students talk to us - this is this module, we have this 
exam(ple) sheet and it's in for this day, and so we relay this information to each other. We know when there's gonna be like a build-up of sheets...

Tutor A went further and explained that he had advised tutor colleagues that a particular student would be asking for specific help and invited them to prepare a response prior to them attending the centre on the following day:

Tutor A: If there is a problem that I can't solve I maybe say come back tomorrow, then I go back to the building [i.e. the postgraduate tutors' shared office] and I say - I've said for someone to come in tomorrow - this is what the question is, maybe you can prepare an answer to give them. The office I work in has...20-30 students, so we have someone from every area of research so if I can't do something I will say...pre-emptively, someone is going to come in tomorrow and ask you this question...

\section{Using the Community to Work Together to Resolve Tensions}

When asked about tensions and disagreements arising between either tutors or tutors and students, there was little evidence that problems were arising. There was reference to one or two students who became such regular users that this became a nuisance and was unfair to others but the situation was resolved through the intervention of the centre manager:

Tutor G: There have been one or two students which pushed some of the tutors a bit in that they were in very often and asking the same thing to a lot of different tutors. It's not common...We've had discussions about whether the centre was used properly, whether some people were abusing...some of us from the centre would have talked about that and then one of the people would have gone and talked to [centre manager].

The interviewees were well aware that should issues arise, there were mechanisms to raise them:

Tutor G: [Centre manager] has meetings every term with the people at the Library - like there is always an email and we try to think of things to mention.

There was little evidence of disagreements between tutors but the following quote shows the spectrum of empathy and understanding, particularly in respect of students from different disciplines:

Tutor F: There has been disagreement with this one tutor about how he interprets students who need help. He can be a bit arrogant - having seen him teach in the centre he doesn't bring that into the centre, he's fine, but when he talks about it afterwards he was like saying this person was an absolute idiot - and I'd say no they're just struggling a bit-people have different skill sets so maths is not their forte - but I've seeing nothing like that - he doesn't bring it to the centre. 


\section{Learning as Becoming}

Working in the centre provides significant opportunity for personal development, mathematically, pedagogically and in terms of more general transferable skills. Tutors were asked about whether working in the centre provided a valuable additional dimension to their working lives. They went on to report how they perceived this work had enabled them to become not only better teachers but better at mathematics. Through the interviews they were able to reify these notions. Some reported becoming 'more professional' and described the professional pride that they took in learning how to solve problems in previously unfamiliar areas, how to better communicate with students and how their practices change in order to 'become better'. Some reported that their experience had impacted upon them sufficiently to consider modifying their career aspirations. Others reported a growing confidence sufficient to enable them to suggest changes to university teaching practices. These aspects will be explored in what follows.

\section{A Valuable Dimension}

The students were asked if they enjoyed working in the centre. This work was an eyeopener for Tutor D who hadn't expected that he would like teaching:

Tutor D: I do. I would say now that I enjoy teaching. I don't think I realised that until I started working in the centre...And doing the support centre work is very one on one, or one on a small group. It has definitely opened my eyes to the fact that I actually do enjoy teaching...

Tutors $\mathrm{C}$ and I valued the opportunity this work gave them to maintain interest in mathematical topics that would otherwise have been left behind:

Tutor C: I think that it keeps you a lot more linked with what you did in your undergraduate [degree] because you are constantly reviewing it - so because a $\mathrm{PhD}$ is so specialised it is so easy to forget and to get rusty.

Tutor I: If nothing else it gives me more experience looking at the other areas of maths that maybe I haven't done them for a while, or I've forgotten details from them. They are not the ones I already teach here so it's nice to see that occasionally because I can remember how things work. They are unlikely to be useful to me again at some point but it's just nice to...

The fact that Tutor I believes that exposure to other areas of mathematics through working in the support centre is "just nice" even when "they are unlikely to be useful to me" is an affirmation of a maturing identity as a mathematician and an important byproduct of participation in the life of the centre.

\section{Becoming Better at Maths Teaching}

There are numerous references in the interviews to "not being a very good tutor" or "not being as good as I would like to be". These notion are reified in the illustrative quotes: 
Tutor E: I noticed when I first came in I was not very good at being a tutor. I wasn't very good at hiding the answer - stuff like that. I try and not solve the problem for them - that's something I definitely did when I was starting - I think I got excited and did it for them.

Tutor F: I can think things in my head but I struggle to explain them to someone else. I think that's my main reason why I want to continue in the mathematics support centre to get more practice, because that it's never been one of my strong points.

Tutor E went on to say that his practice had changed, now working on a whiteboard so that students could not simply take a paper solution away; "they have to copy it down in their own words and ... that hopefully helps their understanding" We have already noted Tutor G (Section Learning as doing Working with students) above who admitted that he had "confused people" by approaching an explanation from a different angle to that of the lecturer. Whilst this can often be a useful strategy (e.g. Tutor D in Section Learning as doing Working with students who by concretising the lecturer's abstract notion of a vector space overcame a blockage in a student's understanding) this awareness led to Tutor G's change in practice. Tutors describe adaption through experience, becoming better, but recognise with some apprehension that they are on a journey and not necessarily there yet:

Tutor H: I would like to think that I can - I don't know what the word is - transmit maths better, in a way that's more understandable for undergrad students...But I can't really know. I think it also depends very strongly on each particular student. The same way of teaching will work for some and not for others. I try to adapt but I am not confident that I am able to do so - at least not just yet.

Through working in the centre, the postgraduates learn about themselves and how they are evolving to become better teachers. Here they refer to developing the confidence to acknowledge their own shortcomings:

Tutor D: I always think it is important to show that just 'cause you are a postgraduate or lecturer you can still make these mistakes and there's nothing wrong with doing that...I am definitely more prepared to take on these questions that I may never have considered before; I feel like my explanation skills have got better; I am better at trying to understand how the student's going to learn this best, to try to tailor an explanation to that; where I can say I have got better is that I am better at detecting when I am hitting a dead end.

Finally, practice in a support centre clearly provides an environment in which interpersonal skills such as empathy and sensitivity can develop:

Tutor B: I am sure I've learnt loads doing it. It's not just about helping them do the homework - you could have a robot do that. It's about showing them there's nothing to be scared of, keeping them calm, inspiring that little bit of confidence in them because that goes an awful long way...I think stuff like that, the human 
side of helping them has been something I've come on a lot...I think that's something I've picked up on a lot more in the last year or two. It's not about the maths as much as it's about this person.

\section{Becoming Better at Mathematics}

Specifically tutors described how they were also learning to be better at mathematics per se:

Tutor I: I can think of one [problem I couldn't solve] which was just a simple thing. It was an integral of some sort. It looked like it should have been very easy. I went back to the office and within five minutes I'd solved it...

Tutor $\mathrm{F}$ went further. He reflected upon being unable to solve a problem in an unfamiliar field - continuum mechanics - that had been presented to him in the centre. Identifying as a mathematician, he believed he ought to know more about this field and endeavoured to address this.

Tutor F: Yes there was one in continuum mechanics - I've actually looked at the lecture notes and sighed and said you [i.e. the tutor himself] should learn about some of this stuff and some of my PhD friends were actually doing that module [at this university, $\mathrm{PhD}$ students study some advanced undergraduate modules] - so when I came back from the centre I said can you get your recent assignment up because I was stuck on that question...So then the solutions came out for that module, I looked at those solutions.

Moreover, he acknowledged that working in the centre provided a good opportunity for widening his mathematical horizons:

Tutor F: I think the centre is great for that because it helps...you explore modules.

Tutor D refers to changes in the way he himself thinks about mathematics, and thinks more broadly around the subject, through his encounters in the centre, again illustrating a strengthening of identity as a mathematician. When asked whether tutoring in the centre has helped his own understanding:

Tutor D: I think it has. I have always understood things in a very particular way, but having to think my way around these other viewpoints has certainly helped give me a broader perspective on the maths I know. I can't give a concrete example but a lot of things I think it's that because of the definition; its helped to see that's why that's the definition. That's certainly been useful. I don't think I have particularly used it in my own research but it's been useful for thinking around the subject.

\section{Career Aspirations}

Some of the tutors aspire to become university lecturers and they were asked about how their experiences in the centre might support their development. They 
referred to the nature of the work in the centre being complementary - "different sort of teaching" from tutorials and problem classes where they know what to expect and are provided with solutions - and how it would prepare them for dealing with unexpected contingencies:

Tutor G: Something I have never done for the department, is the tutorials...On the other hand, in the centre, it's a less formal setting but I have done that - so that's a different aspect of teaching that I have seen only through the centre...[It's a] slightly different sorts of teaching. It's not the same with a small group or a larger group, asking questions, answering questions when you know the topic and you have been preparing for the hour, as opposed to when the question comes as a surprise like there have been times when someone will ask and it's taken me 5 minutes just to remember what the words mean because asking them to clarify what their question is is not just for them - it's also to help me remember what they are working with.

Tutor D enjoyed the work so much that he described modifying his career aspirations so that he might be able to focus more on a teaching-oriented position:

Tutor D: I would still like to carry on this sort of teaching responsibility. I don't know how or I might see a job that's more focussed towards that than the academic research and lecturing...If I had two similar academic job offers and one had more... that would be the one I would probably go for...

Interviewer: [the one with] the teaching in? And this is something that's changed as a consequence of you working in the centre?

Tutor D: I think so.

\section{Skill Development}

When asked about themselves and whether they have developed more skills, it was evident that working in the centre provides opportunity for tutors to do something different to what they would have done as an undergraduate or postgraduate. Several referred to having to develop their communication skills, an aspect which is often quoted as lacking in traditional undergraduate mathematics degrees (Inglis et al. 2012):

Tutor E: Probably. I'm probably more articulate about maths now. I know that I am sometimes not the best communicator - but it's going to improve - I'm aware. So it is helping me to improve on that which I am grateful for. It's good to learnone of the best ways to talk about maths to people is to explain it.

Tutor F: I think I've got better at explaining things, which has never been my forte.

Tutor F went on to note how this was very different to a problems class where he could read a solution prepared by the lecturer and repeat the explanation to the student. In the centre he needed to formulate the explanation for himself and communicate that to the student. 


\section{Growing Confidence to Influence Developments}

The intelligence gained through working in the support centre enables tutors to have informed opinions about how mathematics teaching might develop in the university. Tutor I expressed the concern that when a mathematician teaches a mathematics course to students in another department, here economics, he or she may not be sufficiently well-informed about the backgrounds of the students:

Tutor I: A lot of universities will have taught courses where the mathematicians just teach a thing to economics students... and the mathematicians never see that course. I know a lot of the time they are actually missing on the assumed knowledge so they assume lots of things that people have no idea about.

He went on to give a specific example concerning proof by induction - a technique that the lecturer had assumed, but which was apparently not known by the engineering students that he was helping:

Tutor I: I saw an example in engineering here where the course was taught by a mathematician and everything in it was incredibly basic but it had like a proof by induction in it and they, I think, at least as far as the student was concerned, they had never seen that before and it wasn't taught in this course anywhere, because it was an engineering course. They didn't know what that was.

Tutor B referred specifically to the way that working in the centre might help to ground a prospective lecturer and enable them to acquire valuable experience that might not necessarily be available otherwise. He suggested that working in the centre might enable a lecturer to recall difficulties of their own, and thereby have some empathy for someone who was struggling, and then be in a better position to be able to help them:

Tutor B: The fear would be if you just go through your own career - undergraduate, masters, PhD, postdoc, you end up lecturing, you just keep going and a fair amount of time elapses; if you do that just by yourself you won't remember what it was like back then for yourself and that's really important to...you know... the concept of something back in primary school now - adding numbers or something - I can't imagine what that was like but it's important to remember what these things were like, the tricky bits of learning these things about a derivative, or about an integral or whatever, because when you know that you know exactly what someone is going through and you can help them.

As a follow up question, tutors were asked whether working in a centre would be good professional development for all academic mathematicians. Tutor B believed this to be so because he himself was keen to understand the areas that his students were struggling with. However, he recognised in his response that perhaps not all professors might be able to come down to a level appropriate for some students: 
Tutor B: I think so, completely, yes. Like, some of the best professors I ever had, they just would not be able to explain a simple thing to some students. I don't know if it was just something they thought you need to go and figure out for yourself, maybe it's just a difference of philosophy or if it was just - I often feel in some sense - they just weren't getting why the student wasn't getting it and I wouldn't like to end up like that...I want to always be at the coalface where I can see where the problems are happening, what the tricky bits are and even if it's all easy for me I want to know why someone else would have trouble with it.

Tutors were asked whether they had taken something they had learned from their experiences in the centre back to the department with a view to informing how things might be done differently in mainstream teaching. There was no evidence from the interviews of this taking place but Tutor A went on to describe communication as an area for potential improvement:

Tutor A: No but I think it's something that's missing right now: I'm going to sound very general when I say this, but it's communication between the tutors and the lecturers on the courses, I think this is missing not just in the support centre but also within the examples classes...In my experience of teaching in either, I have never had to report back to anyone who runs a class.

Tutor A referred to a specific issue in statistics teaching that he felt ought to be communicated to lecturers. He became concerned that the students he had seen in the centre appeared to know statistical definitions but their understanding went little beyond that. He felt that a lack of deep learning that he was witnessing in the centre might well not be apparent to lecturers who were marking assignments:

Tutor A: Stuff like...first years in statistics, they have all these definitions, but for the most part it's not deep learning, there's no...for a lot of them there wasn't a sense of this is what you are describing. The lecturers just see, for the most part, the work handed in, which a lot of the time isn't very enlightening in determining whether a student actually understands something - it's generally just surface.

This tutor emphasised the very distinct way in which working in a support centre can garner intelligence about student learning that is not available to a lecturer teaching a very large class of undergraduates:

Tutor A: We have the one-on-one experience that the lecturers don't give them and that's when, in a class of however many first years in a class, very few people are going to speak out, whereas if you are one-on-one with someone in the Library, they kind of have to speak at that point.

Asked whether, if they were in a position of power/responsibility, would they change things, Tutor D suggested that all mathematics undergraduates should have small group support sessions with a postgraduate: 
Tutor D: I would try and organise small support group sessions - four or five students to one postgraduate or one fourth year - maybe once a week particularly for first years...because again, these students that go through their entire degree without getting any of this benefit from one-to-one small group mentoring.

Tutor F noted that if there were better feedback mechanisms from postgraduate tutors to module lecturers this would be helpful, particularly when lecture notes are not clear or are incorrect. He suggested that postgraduates might have more influence in this respect than undergraduates.

Tutor F: Maybe they'll take it more seriously when a PhD students flags up a thing saying this is not good; maybe they'll take it more seriously than just coming from a [undergraduate] student...there was this person doing an environment course and they had some equations - the way they displayed the maths confused me. It was just completely terrible - they needed brackets - I had to presume brackets at certain places, and it was confusing and I had to say, admit to them, as a mathematician how they've written that is confusing - this is not your fault - however your lecturer has written that.

\section{Discussion and Conclusion}

To achieve our overarching goal of understanding the role played by the postgraduate tutors we asked two main research questions: a) What is the role and extent of negotiation and collaboration in postgraduates learning to become mathematics support centre tutors? b) What is the nature of this negotiation and collaboration and what is its impact on individuals and on their self-reported practice? To answer these questions our interview data from nine practising tutors was analysed through the lens of communities of practice. Specifically we used Wenger's components of social learning - learning as experience, learning by doing, learning by belonging and learning as becoming. Because the nature of tutoring in a support centre is quite different from other aspects of the postgraduates' work, they must learn to become tutors and then learn to become better tutors. By and large, this learning is situated 'on the job', drawing first of all upon their own experiences of how they have been taught and what works for them. However, they soon learn that this is insufficient.

We have seen [e.g. Tutor G - Section Learning as doing - Working with students] that when there are multiple ways of approaching a mathematical topic the method known by the tutor may not be the one that has been taught to the student, and to pursue the tutor's preferred approach can lead to confusion. It becomes necessary to learn to adapt and to modify practice. The tutors, who by definition are high-flying academic mathematicians, and particularly the pure mathematicians, think about mathematical concepts in a very abstract and theoretical way. Engineers and other non-mathematicians, (and even some mathematics undergraduates), [e.g. Tutor D - Section Learning as doing - Working with students] find that trying to learn through concrete examples and applications can lead to better understanding and progress. This necessitates a mathematical paradigm shift that some of the postgraduate tutors were able to take on 
board as they developed their teaching. To others this did not come naturally. The ability to improvise and think on one's feet becomes particularly important in the context of a university-wide support service, and the ingenuity to make use of to-hand artefacts, tools and resources to illustrate points of difficulty can be helpful [e.g. Tutor D - Section Learning as doing - Drawing upon resources]. We have seen how tutors draw upon the expertise of more experienced tutors (e.g. Tutors F \& H Section Learning as belonging - Old timers supporting newcomers] and learn by example how to work with students in a support centre.

Perhaps for the first time in their academic lives, the tutors can be faced with uncomfortable challenges. These may be mathematical because they are faced with trying to help a student with an advanced mathematics degree module of which they have no knowledge or experience. Or, they may be faced with problems arising in unfamiliar areas (economics, bioscience, engineering). Challenges can also arise because some of the students seeking help are not particularly able mathematically; they may have weak mathematics backgrounds of which the tutor is unaware. There is increasing awareness within the mathematics support community of the need to support students with specific learning differences such as dyslexia, dyspraxia and Asperger syndrome (Trott 2015). Neurodiversities such as these can increase levels of stress and anxiety when students are faced with the requirement to learn mathematics at university which, in turn, bring particular issues to the fore in a mathematics support centre. The tutor must learn how to deal with these new challenges and with students having different backgrounds and motivations for studying mathematics. We have seen that in these situations of unfamiliar territory the tutors learn to draw heavily on the resources that the students themselves provide (their own lecture notes, their lecturer's notes) [e.g. Tutor E - Section Learning as doing Drawing upon resources] and to work with the students so that they, the tutors, too might undertake the same learning journey. It is at this stage that the support of the community becomes particularly valuable. The tutors can seek help from their partner tutor in the centre, particularly when they are more experienced or have specific knowledge pertinent to the problem in hand. We have seen how tutors work together in a joint enterprise to come to a solution for the student [e.g. Tutors B \& H - Section Learning as doing - Working with students]. We have seen how they come to recognise the skill sets of their peers, developing tools to assist in this [e.g. Tutors A,B \& C - Section Learning as belonging Drawing upon each other] and later draw upon these whilst in the centre.

Within the context of this study, belonging to a large and diverse community of mathematics support tutors was a distinct advantage which helped in numerous ways. Tutors learned to seek help by sharing problems outside of the centre but within their shared office environment, and in turn they offered help to others (e.g. Tutors A \& H Section Learning as belonging - Outside the centre - and still learning). This environment not only enabled improvement of the tutor's own mathematical and pedagogical skills, but provided a forum for sharing more general concerns, for being pre-emptive, and for dealing with contingencies. The group had a collective confidence to raise issues with the centre manager [e.g. Tutor G - Section Learning as belonging - Using the community to work together to resolve tensions] and to proffer solutions. Moreover, several tutors had their awareness raised sufficiently through this work to suggest 
improvements to university mathematics teaching and departmental practices [e.g. Tutor D - Section Learning as becoming - Skill development]. It is apparent that collectively the postgraduate tutors possess a great deal of intelligence concerning the operation of and the practices in the centre and the nature of the problems which students present, that could be mined to inform improvements to the teaching and learning of mathematics throughout the university. Tutors I and B in Section Learning as becoming - Skill development made incisive and poignant remarks in this respect.

We have seen how tutors can refer to themselves as "not being a very good tutor" (Tutor E in Section Learning as becoming - Becoming better at maths teaching) or to others as "being really good at teaching people" (Tutor F in Section Learning as belonging - Old timers supporting newcomers) and how they are able to reify these notions into sets of characteristics which ought to be avoided or adopted. We have been able to demonstrate numerous instances where tutors' identities as teachers are transformed as they progress through their working lives in the centre.

Negotiation and collaboration in this endeavour have come to the fore through our analysis. We have seen this in way that tutors discuss with each other how to practice in the centre, how workloads are distributed, how they use each other's skill sets, how they alert each other to situations likely to have consequences in the support centre such as coursework deadlines. The nature of this negotiation and collaboration is clearly very supportive with numerous instances of joint endeavour in the solution of problems. 'Old timers' have demonstrated repeatedly their willingness to assist newcomers both practically and affectively. Amongst the self-reported impact on individuals we can cite: improved confidence particularly when dealing with unfamiliar mathematical problems; improved communication skills, including the ability to work with nonspecialist users of mathematics.

Our analysis using the lens of communities of practice has enabled us to look systematically at the ways in which the postgraduates learn to tutor. To-date there is but a small number of studies that use the framework offered by this theory to research aspects of university level mathematics education. Those that do highlight the existence of multiple, (sometimes) intersecting communities (researcher mathematicians, mathematics educators, postgraduates, undergraduates). In contrast, the study described herein concentrates on enculturation into and maintenance of a single community albeit one which, as we have seen, exhibits phenomena at the boundaries with mainstream university teaching practices. As noted by Biza et al. (2014) a substantial part of the existing research focuses on proof and the way in which undergraduates must be enculturated into new ways of thinking mathematically. However, as Biza et al. (2014) point out, not all undergraduates aim to become mathematicians. Moreover, there is evidence that many become alienated from university mathematics as their degree course proceeds (Brown et al. 2005). As such there are aspects of the theory of communities of practice, such as that of legitimate peripheral participation (Lave and Wenger 1991) which do not fit well with some characteristics of the undergraduate community. Nevertheless, community and a sense of belonging can act to counteract alienation as explored further in Solomon and Croft (2016). Relatedly, Solomon et al. (2010, p422) demonstrate how a mathematics support centre initially aimed at supporting engineering students "provided the impetus and resources for the generation of a mathematics undergraduate community of practice". Our study, on the other hand relates to postgraduates. For this group we can assume that they 
aim to be involved in research mathematics. We can see them as legitimate peripheral participants in the community of the researcher mathematicians, though this is not directly relevant to their evolving role within the mathematics support centre. Thus a novel contribution of the work we describe here is the application of the theory of communities of practice to explore and understand the role that postgraduate tutors play within mathematics support.

In conclusion, our data has demonstrated that postgraduates do learn to develop as tutors in a mathematics support centre and through collective encouragement, networking and sharing of expertise can learn to become better tutors. We have shown that tutors perceive their sharing of expertise has impacted upon their practices and consequently the evolution of the centre. It is known that the students on the receiving end of their support and, as a consequence, the University, benefit from their expertise and enthusiasm (Grove et al. 2019b) and as such the tutors contribute to a thriving community of mathematics learners. Moreover, there are substantial benefits for the tutors themselves in terms of improved mathematical and pedagogical knowledge and skills, transferable skills of teamworking, communication and empathy, and a widening of their career aspirations.

\section{Recommendations}

We noted earlier that this research is use-inspired and firmly based in Pasteur's quadrant. We have been able to combine the analysis of the data presented here with knowledge and experience based on developing policy and practice in the field of mathematics support throughout the UK. Attention is now turned to the recommendations that we have been able to draw and suggestions for further lines of enquiry.

\section{Implications for Tutor Training}

This analysis has shed light on the way that training for postgraduate tutors might evolve in order that they are enabled to do their job more efficiently and professionally and ensure that students seeking help get the best learning experience possible.

It is well-documented that identifying suitably qualified staff who can help students at their level is a challenge (for example, Starkings 2002). Sutherland and Dewhurst (1999) express concern that university lecturers are not always the best people to be undertaking additional mathematics teaching and support, especially for mathematically weaker students, and by extension this concern might well apply to postgraduate mathematicians too. As Fitzmaurice et al. (2016, p14) note "as tutors are students' first exposure to mathematics learning support it is important that they are trained in order to make their centre an environment that should be welcoming, supportive and non-threatening". So it is all the more important that the training of tutors should attempt to mitigate such concerns.

However, in this paper we have demonstrated that the real learning acquired by postgraduate tutors goes on, not in a one-day training session at the start of their career, but in the learning that is situated in their experience of participation in the life of the centre. Tutor training needs to evolve to reflect this. Our recommendations are based on the following findings emerging from the data analysis: 
- To a large extent tutors' prior experiences shape the way they begin to practice. However, we have cited instances where practice needs to change as tutors begin to appreciate that their approaches are not always achieving the desired results, as in the case of Tutor G in Section Learning as doing - Working with students whose own approach, whilst advanced, was not appropriate for the student being helped, and had to be modified accordingly. Tutor E in Section Learning as becoming Becoming better at maths teaching became aware that at first he wasn't very good at "hiding the answer" but with time developed alternative strategies that concentrated more on the student's understanding.

- Proponents of mathematics support argue that it should be the student and their requirements that are the primary foci of activity in the centre. Thus it is important to know what stage of study the student is at, what is their primary discipline of study at university and whether they have particular learning differences or, in some cases, anxieties. It is apparent that whilst some tutors make an attempt in this direction [e.g. Tutor I in Section Learning as doing - Working with students who recognised that the ways things are done in a mathematics department is always rigorous and formal and that this approach might not be appropriate or necessary for other student groups] others see the mathematics problem itself as being interesting and important [e.g. Tutor D, Section Learning as doing - Working with students who really tries to focus on the question itself] and consequently direct attention to that.

- We have seen that tutors attach value to participating in a community with other tutors and draw extensively upon their expertise [e.g. Student $\mathrm{H}$ in Section Learning and belonging - Drawing upon each other who when faced with a problem from the unfamiliar territory of dynamical systems was able to access support from more knowledgeable colleagues]. Electronic and paper tools to share knowledge, facilitate and encourage networking have proved invaluable [Tutors A \& C Section Learning as doing - Working with students]. Clearly such expertise is dynamic - changing as tutors' experience grows both in the centre and more widely through their research and other teaching activities.

- It is clear that the old-timers possess knowledge of use to newcomers and are willing to share this. Partnering has proved helpful in several instances cited [e.g. Tutor A in Section Learning as belonging - Outside the centre - and still learning who noted that "a fourth year [tutor] comes along whose been doing this a long time and has probably come across that problem themselves" and Tutor H: "you can copy things you really like that they do".

So the most significant recommendation we can make would be that a one-day training session at the start is supplemented by an on-going set of regular continuing professional development opportunities in recognition of the fact that most learning is situated in practice. These opportunities would be intended to capture the dynamic nature of the learning that is taking place and specifically address the following points. They would:

- encourage tutors to periodically reflect on their own developing skills - mathematical and pedagogical - and be persuaded to share this information with other tutors.

- encourage tutors to share, in an open and constructive way, how they attend to the individual learning needs of students so that more emphasis can be placed on making the learning experience of those visiting for help more student-centred. 
- ensure that it is not left to chance that a newcomer observes some characteristic of good teaching developed through experience by the old-timers.

- ensure that mechanisms are put in place so that tutors are aware of the skills of others and are encouraged to make use of these.

We recognise that making this change has financial resourcing implications and requires additional commitment from the tutors themselves. However, if the centre is to make best use of the talents of its tutors we believe these are fundamental steps in developing excellence. This particular centre is in the fortunate position of having a healthy number of tutors and it is natural therefore to seek to take advantage of the community structure, its various levels of experience and wideranging expertise. We believe these recommendations are transferable to other institutions where multiple tutors work.

\section{Implications for the Centre and Directions for Research}

We now draw attention to three areas in which more work is required in order to build upon this body of knowledge and understand how students from all disciplines requiring mathematics can be better supported.

Firstly, we have noted that in its early days the centre attracted proportionally more users from outside the discipline of the mathematical sciences. In later years mathematics undergraduates have become the main users and their usage of this particular centre has recently been explored elsewhere (Grove et al. 2019b). Given the ongoing 'mathematics problem' described in the Introduction and the continued growth of support centres in other institutions, it would not be unreasonable to assume that there are plenty of students in this particular university who would benefit from mathematics support, but who are not taking advantage of it. In the light of the findings by Starkings (2002) and Sutherland and Dewhurst (1999) it is indeed possible the whilst mathematics postgraduates are excellent tutors to undergraduate mathematicians, offering mathematics support to non-specialist students requires a different skill set. Who are the people best-qualified to tutor in a mathematics support remains an important open question.

Secondly, although targeted at students of other disciplines most providers of universal mathematics support report that mathematics students are the major users, notwithstanding the fact that the raison d'etre for most centres was the support of nonspecialists. These students are sufficiently well-qualified mathematically to have been admitted to a mathematics degree and, unlike students in many other disciplines, have specifically chosen to study the subject at university. Why this group makes substantial use of a support centre is intriguing when we consider that departmentally-based learning opportunities (problems classes, personal tutors, workshops) are additionally offered to these students. Solomon et al. (2010) argue that for female mathematics students in particular a support centre offers 'neutral ground' enabling a power shift in the (usually male) tutor:student relationship and enabling one-to-one discussions that would not take place in a formal class. Croft and Lawson (2017) offer their perspective on why mathematics support centres appear to be so appealing to many mathematics undergraduates and suggest, inter alia, that the availability of physical space and its configuration promote collaboration. It appears that many mathematics undergraduates 
do not wish to adopt a solitary, competitive approach to studying mathematics but instead value the undergraduate communities of practice that support centres can encourage. But this work is insufficiently developed and the field would benefit from a thorough understanding of this phenomenon.

Finally, very little is known about the practices of tutors in a support centre and how they interact with students. The data presented herein provides insight but has been gathered from the perspective of the tutors. Walsh (2017) has attempted to explore this further through analysis of video recordings of three postgraduate tutors working with engineering and science students in a support centre. Whilst clearly a small-scale study, the findings were troubling. Tutors tended to align their practice with that of a traditional lecturing style, i.e. it was very didactical, providing little opportunity for questioning and dialogue. He refers to the tutors lacking various pedagogical skills necessary for high quality learning. Observational studies could reveal much more about what actually goes on and explore what is effective tutoring within a support centre environment. We would point out though that such studies are fraught with ethical and practical challenges. The act of seeking consent to observe student users who drop-in for help as they explain their difficulties and anxieties may well put off many of the students in most need of help.

The recommendations for tutor training along with the research questions we have posed are offered for researchers and practitioners in mathematical sciences and mathematics education to consider as university mathematics teaching evolves to embrace and enthuse future generations of students. Further, this work contributes to a small but growing body of research literature concerned with bridging the gap between theory and practice in university mathematics education at a time when, to quote Artigue in Sierpinska and Kilpatrick (1998), such rapprochement is vital, as the community seeks to respond to significant changes affecting the higher education sector.

Acknowledgements We would like to thank Professor Barbara Jaworski for her helpful and informative comments upon an earlier version of this paper and for the anonymous comments following peer review that have greatly helped prepare this version.

\section{Compliance with Ethical Standards}

Conflict of Interest On behalf of all authors, the corresponding author states that there is no conflict of interest.

\section{Appendix: Illustrative Interview Questions}

1. The mathematical background of the tutor, their ambitions and their motivation for working in the centre: give some details about your current research area and stage of study? For how long have you tutored in the centre? What was your motivation for doing this work?

2. What the tutors know and think about mathematics support: what do you think is the purpose of a mathematics support centre? Do you think such a service is necessary? As an undergraduate did you ever benefit from something like this? 
3. The practices tutors adopt whilst working in the centre, the ethos of that work and the environment they were helping to create: when you enter the centre at the start of a session describe what it is that you do and how you conduct yourself; Do you endeavour to find out something about the course students are studying, and if so do you treat different groups in different ways? What do students say to you, and how do you respond? Can you describe your tutoring style? Has this changed through experience? Do you draw upon any tools to help you? To what extent, if any, do you liaise with other postgraduates working in the centre during a session? Can you think of examples? Afterwards, do you ever go away and work on some problem that you faced in the centre? Do you ever reflect on what has happened and whether you might have done something differently? Have you mentored, trained or helped other postgraduates? Can you think of instances where there have been significant challenges, tensions or disagreements and if so how were these resolved?

4. Tutors' views concerning postgraduates working in the centre; what do you think are the benefits (if any) of using postgraduates as tutors? Do postgraduates bring anything different to what might be offered by academic staff? What are the attributes of a good centre tutor and have you witnessed any of these? Do postgraduates have a role to play in feeding back findings into mainstream teaching? Are you aware of this being done? Do the postgraduates work together at all? Do you share problems and difficulties? Have you changed your practice as a result of talking to or observing others? Are you aware of skills that other postgraduates have that you do not?

5. The skills and qualities tutors think they have been able, or hope, to develop through this work: can you talk about any skills you have developed through this role? Can you think of anything you are better at now as a consequence of this work? Has the role made you aware of any of your shortcomings? Has working in the centre made you consider your own career ambitions?

Open Access This article is distributed under the terms of the Creative Commons Attribution 4.0 International License (http://creativecommons.org/licenses/by/4.0/), which permits unrestricted use, distribution, and reproduction in any medium, provided you give appropriate credit to the original author(s) and the source, provide a link to the Creative Commons license, and indicate if changes were made.

\section{References}

British Educational Research Association (BERA). (2011). Ethical Guidelines for Educational Research [Online]. Retrieved from https:/www.bera.ac.uk/wp-content/uploads/2014/02/BERA-EthicalGuidelines-2011.pdf. Accessed 2 May 2019.

Biza, I., Jaworski, B., \& Hemmi, K. (2014). Communities in university mathematics. Research in Mathematics Education, 16(2), 161-176.

Braun, V., \& Clarke, V. (2006). Using thematic analysis in psychology. Qualitative Research in Psychology, 3(2), 77-101.

Brown, M., Macrae, S., Rodd, M., \& Wiliam, D. (2005). Full report of research activities and results: Students experiences of undergraduate mathematics: Grant R000238564. Swindon: Economic and Social Research Council.

Creswell, J. W. (2008). Educational research: Planning, conducting, and evaluating quantitative and qualitative research (3rd ed.). Upper Saddle River: Pearson Education.

Creswell, J. W., \& Miller, D. L. (2000). Determining validity in qualitative inquiry. Theory Into Practice, 39(3), 124-130. 
Croft, A. C., \& Grove, M. J. (2016). Mathematics and statistics support centres: Resources for training postgraduates and others who work in them. MSOR Connections, 14(3), 3-13.

Croft, A.C. \& Lawson, D.A. (2017). Improving mathematics education: What can we learn from 25 years of mathematics support? Mathematics Today, October 2017, 196-199.

Duah, F.K. (2017). Students as partners and students as change agents in the context of university mathematics, PhD Thesis, Loughborough University. Retrieved from https://dspace.lboro.ac.uk/dspacejspui/bitstream/2134/25556/1/Thesis-2017-Duah.pdf Accessed 27 September 2018.

Fitzmaurice, O., Cronin, A., Ní Fhloinn, E., O'Sullivan, C., \& Walsh, R. (2016). Preparing tutors for mathematics learning support. MSOR Connections, 14(3), 14-20.

Foster, B. (2005). MATHS-AID. MSOR Connections, 5(3), 1-8.

Grove, M. J., Kyle, J., \& Cox, W. (2006). The weakest link? Supporting the postgraduate teaching assistant. In D. Corcoran \& S. Breen (Eds.), Proceedings of second international science and mathematics education conference (pp. 116-123). Dublin: St Patrick's College, Drumcondra, Dublin.

Grove, M. J., Croft, A. C., Lawson, D. A., \& Petrie, M. (2019a). Community perspectives of mathematics and statistics support in higher education: The role of the staff member. Teaching Mathematics and its Applications, 38(1), 43-59.

Grove, M.J., Guiry, S. \& Croft, A.C. (2019b). Specialist and more-able mathematics students: understanding their engagement with mathematics support. International Journal of Mathematical Education in Science and Technology https://doi.org/10.1080/0020739X.2019.1603407.

Hawkes, T., \& Savage, M. D. (2000). Measuring the mathematics problem. London: Engineering Council.

Inglis, M., Croft, A. C., \& Matthews, J. (2012). Graduates' Views on the Undergraduate Mathematics Curriculum. Birmingham: Maths, Stats \& OR Network and National HE STEM Programme.

King, A. (2008). In vivo coding. In L. M. Given (Ed.), The sage encyclopedia of qualitative research methods (pp. 473-474). Thousand Oaks: Sage.

Lave, J., \& Wenger, E. (1991). Situated learning: Legitimate peripheral participation. Cambridge: Cambridge University Press.

Lawson, D. A., Halpin, M., \& Croft, A. C. (2001). After the diagnostic test - What next? Evaluating and enhancing the effectiveness of mathematics support centres. MSOR Connections, 1(3), 19-23.

Lawson, D. A., Croft, A. C., \& Halpin, M. (2003). Good Practice in the Provision of Mathematics Support Centres (2nd ed.). Birmingham: LTSN Maths, Stats \& OR Network.

MacGillivray, H. \& Wilson, T. (2008). Quantitative diversity: Disciplinary and cross-disciplinary mathematics and statistics support in Australian universities. Australian Learning and Teaching Council. Retrieved from https://eprints.qut.edu.au/106986/3/106986.pdf Accessed 27 September 2018.

Mackenzie, H., Tolley, H., Croft, A. C., Grove, M. J., \& Lawson, D. A. (2016). Senior management perspectives of mathematics and statistics support in higher education: Moving to an 'ecological' approach. Journal of Higher Education Policy and Management, 38(5), 550-561.

Nardi, E. \& Iannone, P. (2004). On the fragile yet crucial relationship between mathematicians and researchers in mathematics education. Proceedings of the $28^{\text {th }}$ conference of the International Group for the Psychology of mathematics education. Vol. 3 pp401-408.

O’Sullivan, C., Mac an Bhaird, C., Fitzmaurice, O., \& Ní Fhloinn, E. (2014). An Irish mathematics learning support network (IMLSN) report on student evaluation of mathematics learning support: Insights from a large scale multi-institutional survey. Retrieved from https://www.teachingandlearning.ie/wpcontent/uploads/2016/11/IMLSN.pdf Accessed 27 September 2018.

Sierpinska, A., \& Kilpatrick, J. (Eds.). (1998). Mathematics Education As a Research Domain: A Search for Identity: an ICMI Study. Dordrecht: Kluwer Academic Publishers.

Smith, A. (2004). Making mathematics count. London: The Stationery Office.

Solomon, Y., \& Croft, A. C. (2016). Understanding undergraduate disengagement from mathematics: Addressing alienation. International Journal of Educational Research, 79, 267-276.

Solomon, Y., Croft, A. C., \& Lawson, D. (2010). Safety in numbers: Mathematics support centres and their derivatives as social learning spaces. Studies in Higher Education, 35(4), 421-431.

Starkings, S. (2002). Mathematical and statistical support service at South Bank University. MSOR Connections, 2(3), 13-15.

Stokes, D. E. (1997). Pasteur's quadrant - Basic science and technological innovation. Washington, DC: Brookings Institution Press.

Sutherland, R., \& Dewhurst, H. (1999). Mathematics Education: Framework for Progression from 16-19 to $H E$. Bristol: University of Bristol, Graduate School of Education.

Tolley, H. \& Mackenzie, H. (2015). Senior Management Perspectives on Mathematics and Statistics Support in Higher Education. Loughborough: Sigma. 
Trott, C. (2015). The neurodiverse mathematics student. In M. J. Grove, A. C. Croft, J. Kyle, \& D. A. Lawson (Eds.), Transitions in Undergraduate Mathematics Education (pp. 209-226). Birmingham: The University of Birmingham \& Higher Education Academy.

Walsh, R. (2017). A case study of pedagogy of mathematics support tutors without a background in mathematics education. International Journal of Mathematical Education in Science and Technology, 48(1), 67-82.

Wenger, E. (1998). Communities of practice: Learning, meaning, and identity. Cambridge: Cambridge University Press.

Wenger, E., McDermott, R., \& Snyder, W. (2002). Cultivating communities of practice: A guide to managing knowledge. Boston: Harvard Business Press.

Publisher's Note Springer Nature remains neutral with regard to jurisdictional claims in published maps and institutional affiliations. 